\title{
A STUDY OF LIGHT POINT DEFECT REMOVAL BY SC-1 CHEMISTRIES*
}

\author{
P. J. Resnick, C. L. J. Adkins, C. A. Matlock, \\ M. J. Kelly, P. J. Clews, N. C. Korbe \\ Sandia National Laboratories \\ Albuquerque, NM 87185
}

\begin{abstract}
Recent research has shown that dilute SC-1 chemistries, when combined with high frequency sonication (megasonics) can be highly effective for particle removal. The mechanism by which the SC-1 chemistry facilitates particle removal remains unclear. Experiments were performed under extremely dilute conditions in order to help elucidate a cleaning mechanism. Results indicate that hydrogen peroxide, under extremely dilute conditions, is not necessary for effective particle removal. The increase in haze commonly attributed to increased surface roughness is not observed when sufficiently dilute ammonium hydroxide (e.g., 1:2700) is used. The role of hydrogen peroxide, when more concentrated chemistries are used, may be simply to mitigate surface etching and roughening, rather than to play an active role in particle removal.
\end{abstract}

\section{INTRODUCTION}

In a study of SC-1/megasonic cleaning for small particles $(\leq 0.20 \mu \mathrm{m})$, an empirical response surface model was previously generated [1]. Megasonic power was the dominant factor for these cleans, with temperature and chemical ratio $\left(\mathrm{NH}_{4} \mathrm{OH}: \mathrm{H}_{2} \mathrm{O}_{2}\right)$ modifying the effect of power. As a continuation to the original study, a matrix was constructed and performed using ultra-pure water without any SC-1 chemistry at various megasonic power and temperature set points. The particle removal response surface from the DI water experiments was substantially different than the response surfaces generated when dilute SC-1 solutions were used. The disparate nature of these two response matrices suggested that additional experimentation was warranted in the regime between water-only and the previously studied dilute chemistries such as 1:100:6900

\footnotetext{
"This work was performed at Sandia National Laboratories, which is operated for the U.S. Department of Energy under contract no. DE-AC04-94AL85000. This work was funded through a cooperative research and development agreement with SEMATECH.
} 
$\left(\mathrm{NH}_{4} \mathrm{OH}: \mathrm{H}_{2} \mathrm{O}_{2}: \mathrm{H}_{2} \mathrm{O}\right)$. The objective of performing experiments in this "ultradilute" regime was not necessarily to optimize an existing clean, but rather to develop insight into the chemical action involved in the SC-1 megasonic clean. By developing a more fundamental understanding of the way in which the cleaning chemistry interacts with the wafer surface, optimized SC-1 chemistries can be used with more confidence for future generation device fabrication.

\section{EXPERIMENTAL}

A design of experiments (DOE) matrix was constructed to study particle removal efficacy with various ultra-dilute SC-1 chemistries in a megasonic bath. The study was performed in a Verteq focused beam megasonic, and particle metrology was performed on a Tencor Surfscan 6200. The $\mathrm{NH}_{4} \mathrm{OH}$ and $\mathrm{H}_{2} \mathrm{O}_{2}$ concentrations were varied from 0 to $5000 \mathrm{ppm}$ at fixed megasonic power and temperature $\left(150\right.$ or $200 \mathrm{~W}, 25^{\circ} \mathrm{C}$ or $\left.45^{\circ} \mathrm{C}\right)$. The addition of light point defects (LPDs) to pre-cleaned wafers was the measured response for these experiments.

Following the DOE, two chemistries with different oxidation potentials were selected with which to perform open circuit potential (OCP) measurements. The first chemistry was a 1:80:2600 dilute $\mathrm{SC}-1$, and the second chemistry was a 1:0:2700 aqueous ammonia solutions (no $\mathrm{H}_{2} \mathrm{O}_{2}$ added). OCPs were measured with both $\mathrm{n}$ and $\mathrm{p}$-type $\mathrm{Si}<100>$ (both high and low resistivity material), under both bright and dark lighting conditions. Bright light conditions were created by illuminating the sample with a Balzers $50 \mathrm{~W}$ tungsten halogen inspection lamp, positioned approximately $30 \mathrm{~cm}$ from the liquid surface. Dark processing conditions were created by covering the test cell with black plastic and turning off room lights in the bay. OCP data were recorded with an Accumet $\mathrm{pH}$ meter model 50. The values obtained from the $\mathrm{pH}$ meter were verified with a Keithley model 617 electrometer. Wafers were precleaned in 100:1 HF to remove any backside oxide. Contact to the backside of the wafers was made using indium foil pressed onto the wafers, and contact to the indium was made with a platinum disk. All measurements were made relative to a saturated calomel electrode (SCE).

Finally, cleaning efficacies for the removal of silicon nitride particles $(0.11-0.30$ $\mu \mathrm{m})$ deposited from an aerosol were measured under conditions which produced substantially different $\mathrm{OCP}$ values. The wafers for these experiments were pre-cleaned in a 1:4:64 SC-1 solution at $45^{\circ} \mathrm{C}$ with $200 \mathrm{~W}$ applied megasonic power. 


\section{RESULTS}

In the first experimental matrix, the addition of LPDs to pre-cleaned wafers processed in ultra-dilute $\mathrm{SC}-1$ chemistries was studied. Because extremely dilute chemistries were used (ppm range), reproducible cleaning efficiency data were difficult to obtain. Therefore, the addition of LPDs to pre-cleaned wafers was the measured response. Light point defect addition increased as the concentration of hydrogen peroxide was increased and ammonium hydroxide reduced. Calculated solution $\mathrm{pH}$ values were found to vary primarily with the ammonium hydroxide concentration and only slightly as a function of the hydrogen peroxide concentration. LPD counts did not correlate directly to calculated solution $\mathrm{pH}$ values (based on a $\mathrm{pH}$ of 5.9 in equilibrium with cleanroom air). The solution oxidation potential was calculated using the method of Pourbaix [2]. The trend was found to be similar to the LPD addition trend, although no causal relationship can yet be deduced. These results are shown in Figures 1 and 2.

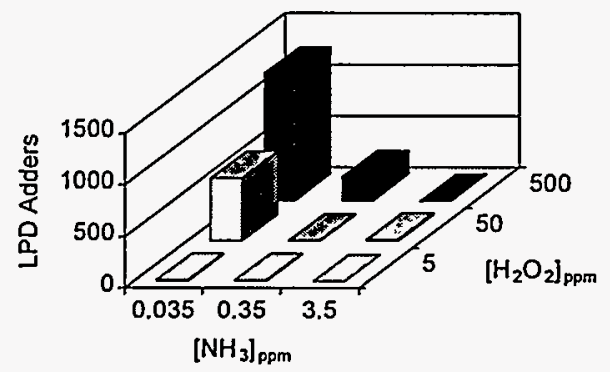

Figure 1. Light point defect addition as a function of process chemistry.

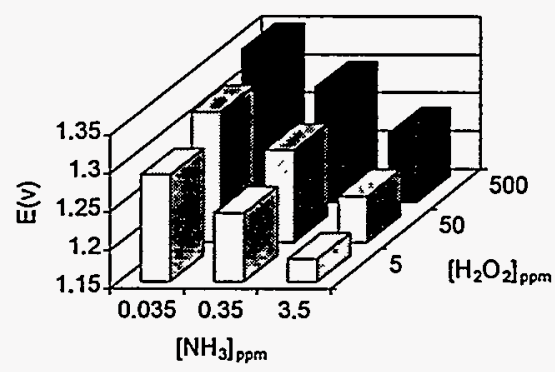

Figure 2. Calculated oxidation potentials (NHE) as a function of process chemistry.

Because LPD addition was observed to trend with the solution oxidation potential, additional electrochemical experiments were performed to assess the significance of electrochemistry in the SC-1 clean.

Open circuit potential values were obtained for both $\mathrm{n}$ and $\mathrm{p}$-type silicon in 1:80:2600 and 1:0:2700 chemistries. These chemistries, which are significantly more concentrated than those used in the previous experiments, were chosen because they have similar $\mathrm{pH}$ values (9.7 and 10.6, respectively), and are in a concentration regime where moderate particle removal performance without applied megasonic power should be expected. The measured OCPs generally trended more positive with time, indicative of surface passivation. The OCP values are plotted in Figures 3 and 4 . Most notable is that the OCP drifted very little when n-type silicon was placed in the aqueous ammonia solution (1:0:2700 chemistry), and the OCP values were essentially independent of wafer doping 


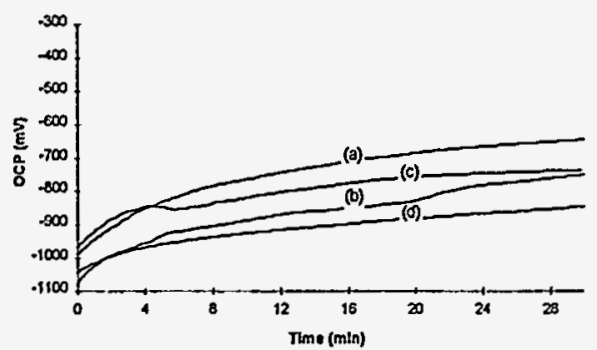

Figure 3a. OCP (wrt SCE) for n-type $\mathrm{Si}$ in 1:80:2600 SC-1 chemistry.

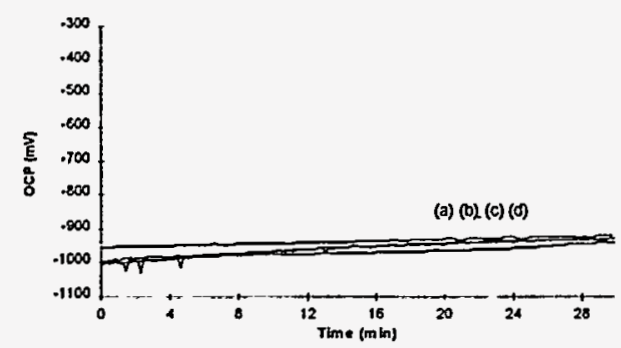

Figure 4a. OCP (wrt SCE) for n-type Si in 1:0:2700 aqueous ammonia.

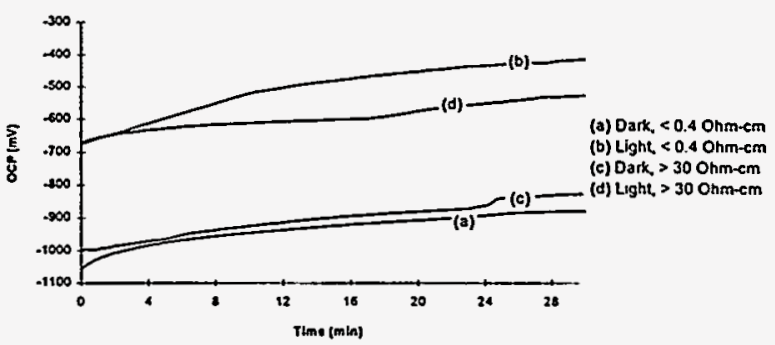

Figure 3b. OCP (wrt SCE) for p-type Si in 1:0:2700 aqueous ammonia.

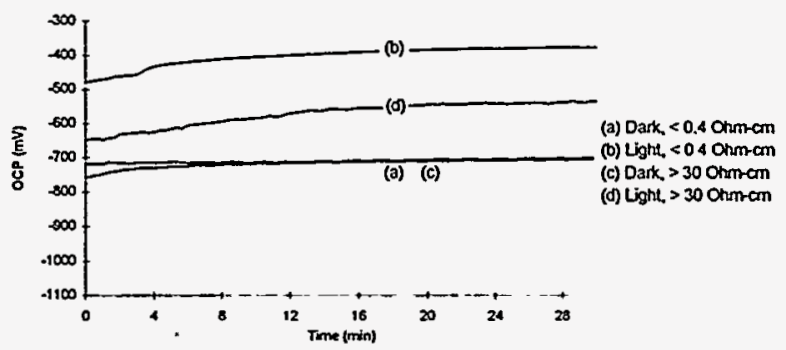

Figure 4b. OCP (wrt SCE) for n-type Si in 1:0:2700 aqueous ammonia.

level and ambient lighting conditions (Figure 4a). When p-type silicon was placed in the same solution, stable OCPs were obtained only under dark conditions (Figure 4b). These data indicate that photo-assisted redox chemistry, (e.g., surface oxidation), does not occur when n-type silicon is processed in aqueous ammonia solutions (no hydrogen peroxide present). Thus, if surface oxidation/etching are requisite for an effective cleaning process, the cleaning efficacy of n-type silicon in dilute aqueous ammonia should differ significantly from the efficacy obtained in ammonia solutions containing hydrogen peroxide.

Cleaning efficacy data were collected for the removal of $\mathrm{Si}_{3} \mathrm{~N}_{4}$ particles $(0.11-0.30$ $\mu \mathrm{m})$ from hydrophilic $\mathrm{Si}<100>$ surfaces. The results from these experiments, which were performed at $45^{\circ} \mathrm{C}$ with no applied megasonic power, are shown in Figure 5 . The mean cleaning efficiency is slightly higher when no hydrogen peroxide is present in the cleaning solution. There is no significant difference in these data between cleans which were performed under dark conditions and cleans performed under bright light conditions. Overall, p-type wafers had slightly higher cleaning efficiency and a significantly smaller spread to the data than n-type. The interquartile range (IQR) for ptype silicon was $7.2 \%$, and for $n$-type the IQR was $18.9 \%$ (noting that all outliers were from n-type silicon). Although the differences in wafer type on cleaning performance are quite small, the processing appears to be slightly more robust with p-type silicon. No significant difference was noted between light and dark cleaning conditions for either $n$ or p-type silicon. If cleaning efficacy is strongly influenced by an etch/oxidation 


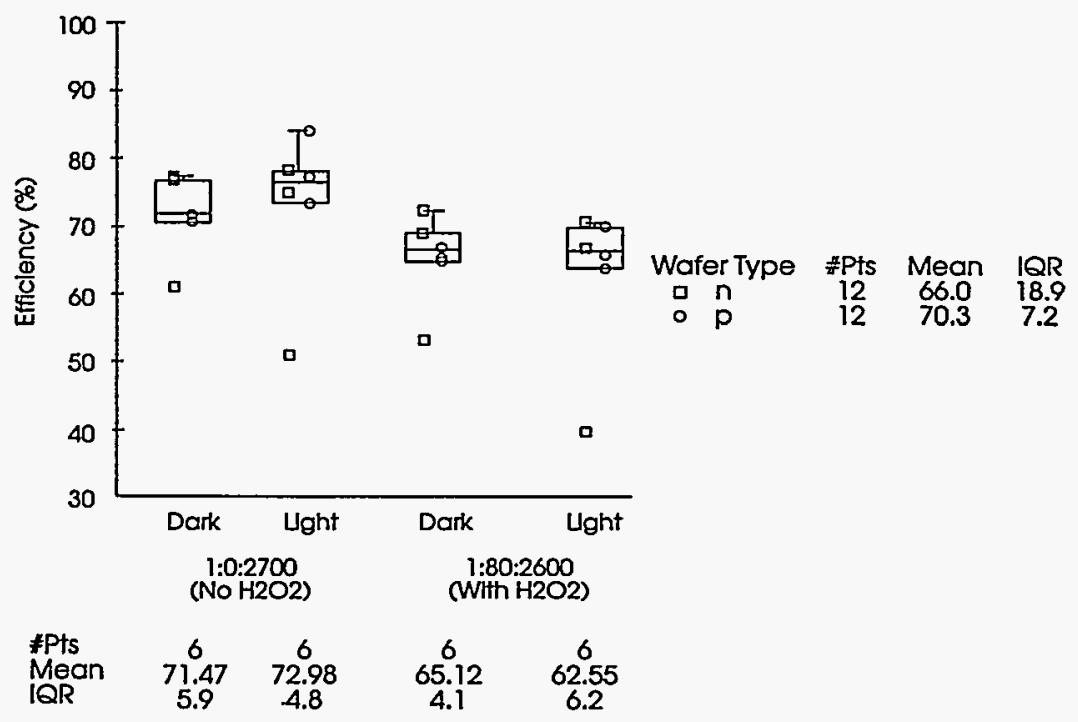

Figure 5. Particle removal efficiency with and without hydrogen peroxide under light and dark processing conditions.

mechanism, and assuming that the etch/oxidation processes are not kinetically limited, then some difference in cleaning performance should be noted under conditions where large differences in OCP were measured. Atomic force microscopy (AFM) methods to measure the extremely low etch rates expected under these conditions are currently being explored.

Historically, hydrogen peroxide has been added to the SC-1 clean to suppress surface roughness generated by the alkaline etch of $\mathrm{Si}\langle 100\rangle$, and to aid in the removal of organic contamination. As this work has been focused primarily on particle removal, no effort has yet been made to study the impact on organic removal by reduction or elimination of $\mathrm{H}_{2} \mathrm{O}_{2}$. Although somewhat ambiguous, haze is commonly used as a metric for wafer cleaning performance. Haze can be defined as the ratio of light scattered from the surface to the light illuminating the surface (a source of noise in scattered light particle detection), and increased surface noise can be attributed to increased surface roughness [3]. In aqueous ammonia solutions at sufficiently dilute chemistries (e.g., 1:2700 dilution), high cleaning efficiencies have been observed without producing measurable increases in haze. Haze delta values are shown in Figure 6. There are notable differences for wafers processed under bright and dark conditions. Higher haze values are produced when wafers are processed with $\mathrm{H}_{2} \mathrm{O}_{2}$ under dark conditions, or without $\mathrm{H}_{2} \mathrm{O}_{2}$ under bright conditions. The conditions which result in increased haze do not correlate with increased (or decreased) cleaning efficacy.

Finally, experiments were performed with dilute ammonia solutions using applied megasonic power to determine if acceptable particle removal efficiencies can be achieved 


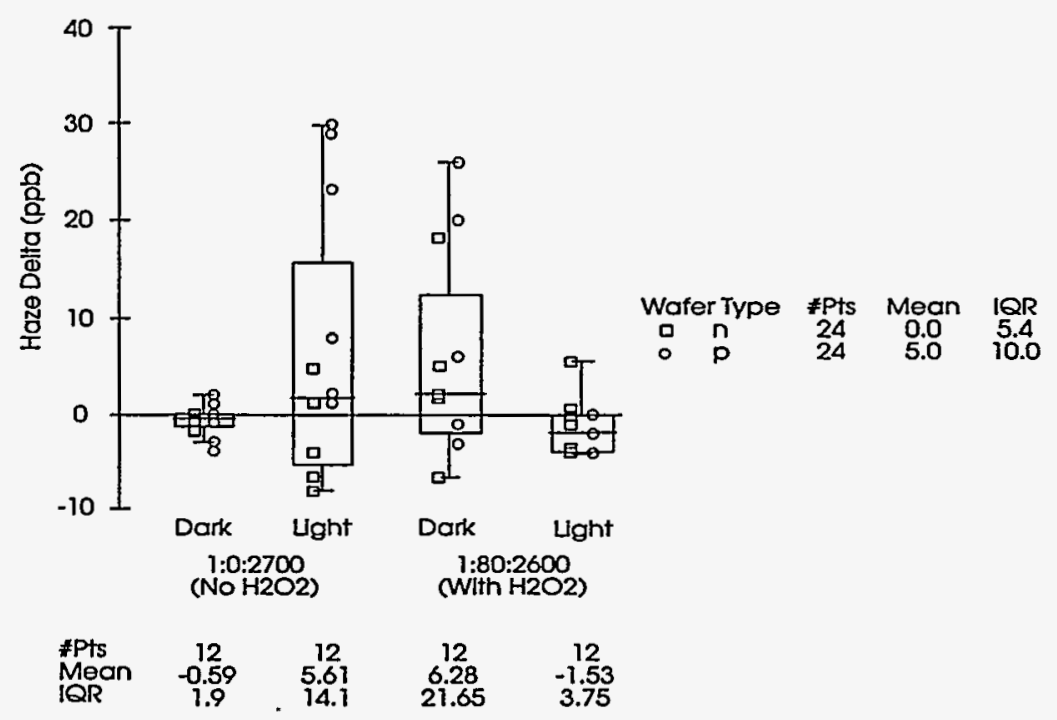

Figure 6. Delta haze values with and without hydrogen peroxide under light and dark processing conditions.

without hydrogen peroxide present. Cleaning efficiencies of greater than $95 \%$ were obtained at $45^{\circ} \mathrm{C}$ with $200 \mathrm{~W}$ of megasonic power applied. No significant increase in haze was measured on these wafers, indicating that the use of megasonic power did not promote surface roughness.

\section{DISCUSSION}

First, open circuit potential measurements have been used to determine conditions where passivation of the silicon surface is likely to occur. Ambient lighting, wafer type ( $\mathrm{n}$ or $\mathrm{p}$ ), and solution oxidation potential influence the passivation characteristics of the silicon surface in solution. Conditions have been identified where photo-assisted surface reactions are occurring. For example, n-type silicon, without peroxide present, appears quite stable (OCP is not effected by lighting conditions). However, p-type silicon without peroxide shows significant shifts in OCP when processed under different lighting conditions.

Second, the change in the haze values were also noted during these experiments. Although other surface phenomena can be attributed to increased haze (e.g., organic films, grain boundaries), the only explicable source of haze during these experiments is surface roughness. The increase in surface roughness can be caused by incomplete etching of the chemical oxide on SC-1 pre-cleaned wafers, or the selective etching of the 
$\mathrm{Si}<100>$ plane [4]. The latter mechanism assumes that the chemical oxide is etched away prior to the attack of the silicon substrate. According to Schnakenberg, et. al. [5], etching is facilitated by interaction of conduction band electrons with adsorbed $\mathrm{H}_{2} \mathrm{O}_{2}$, or increased population of the conduction band in p-type silicon with photoelectrons by illumination. The haze delta values were lowest when the $\mathrm{Si}\langle 100\rangle$ was processed without $\mathrm{H}_{2} \mathrm{O}_{2}$, under dark conditions. Low haze deltas were also observed when the wafers were illuminated during processing with $\mathrm{H}_{2} \mathrm{O}_{2}$ added to the cleaning solution. The former condition should give rise to very low etch rates (few photoelectrons and no adsorbed $\mathrm{H}_{2} \mathrm{O}_{2}$ ); the latter condition should give rise to a smooth etched surface [5]. The conditions which give rise to substantially increased haze are processing without $\mathrm{H}_{2} \mathrm{O}_{2}$ under light conditions, or dark processing with $\mathrm{H}_{2} \mathrm{O}_{2}$. These conditions result in either no adsorbed $\mathrm{H}_{2} \mathrm{O}_{2}$ or reduced photoelectrons. Increased haze under these conditions may be the result of preferential etching of the $<100>$ plane when $\mathrm{H}_{2} \mathrm{O}_{2}$ is omitted, or incomplete etching of the native oxide when $\mathrm{H}_{2} \mathrm{O}_{2}$ is included in the cleaning solution and processing is performed under dark conditions.

It is important to note that, although systematic differences in haze and OCP values were observed depending on lighting and solution chemistry, no such systematic differences were observed in actual cleaning performance. These data indicate that surface modification, under conditions of dilute chemical processing, do not correlate to cleaning efficacy. These results are consistent with the findings of Itano, et. al. [6], who determined that particle removal efficiency is not always proportional to the silicon etch rate in SC-1 type chemistries.

When a sufficiently dilute aqueous ammonia solution is used, it is not clear what role hydrogen peroxide plays with respect to particle removal. Other researchers $[7,8]$ have shown that iron deposition from SC-1 corresponds to iron concentration in the hydrogen peroxide. Thus, a desirable reduction in metal contamination caused by the SC-1 chemistry should be accomplished by reduction or elimination of $\mathrm{H}_{2} \mathrm{O}_{2}$ in the $\mathrm{SC}-1$ clean.

\section{CONCLUSION}

Although lighting conditions, wafer resistivity and doping levels are seen to influence the removal of LPDs during processing in extremely dilute (ppm range) solutions, these phenomena are not observed when somewhat more concentrated chemistries (those which yield effective particle removal) are used. These appear to be second order effects that have little impact on cleaning performance in an otherwise efficacious clean. OCP data, along with haze values obtained during cleaning experiments, indicate that etching/passivation of the surface depends on both $\mathrm{NH}_{4} \mathrm{OH}$ and $\mathrm{H}_{2} \mathrm{O}_{2}$ concentrations, as well as wafer type and lighting conditions. Process parameters conducive to etching do 
not necessarily result in more efficacious cleans with respect to particle removal. Although etching of native oxide may be part of the cleaning mechanism when more concentrated chemistries are used, with dilute chemistries it appears that effective cleaning can occur with little or no removal of material from the wafer surface. In traditional concentration chemistries, the addition of $\mathrm{H}_{2} \mathrm{O}_{2}$ is required to suppress the surface roughness that is created by the selective alkaline etch of $\mathrm{Si}<100>$. When sufficiently dilute aqueous ammonia solutions are used on hydrophilic wafers (without $\mathrm{H}_{2} \mathrm{O}_{2}$ addition), alkaline attack and roughening of the silicon is minimal, yet effective particle removal is still obtained.

\section{REFERENCES}

1. P. J. Resnick, C. L. J. Adkins, P. J. Clews, E. V. Thomas, S. T. Cannaday in Cleaning Technology in Semiconductor Device Manufacturing, J. Ruzyllo and R.E. Novak, Editors, p. 450, PV 94-7, The Electrochemical Society, Inc., Pennington, NJ (1994).

2. M. Pourbaix, Atlas of Electrochemical Equilibria in Aqueous Solutions, Pergamon, Oxford (1966).

5. J. C. Stover, Optical Scattering: Measurement and Analysis, p. 166, McGraw-Hill, New York (1990).

4. E. D. Palik, V. M. Bermudez, O. J. Glembocki, J. Electrochem. Soc., 132, 871 (1985).

5. U. Schnakenberg, W. Benecke, B. Lochel, S. Ullerich, P. Lange, Sensors and Actuators, A25-27, 1 (1991)

6. M. Itano, F. W. Kern Jr., R. W. Rosenberg, M. Miyashita, I. Kawanabe, T. Ohmi, IEEE Trans. Semiconductor Manufacturing, Vol. 5, No. 2 (1992).

7 O. J. Antilla, M. V. Tilli, M. Schaekers, C. L. Claeys, J. Electrochem. Soc., 139, 1180 (1992).

8 M. Meuris, S. Verhaverbeke, P. W. Mertens, M. M. Heyns, L. Hellemans, Y. Bruynseraede, A. Philipossian, Jpn. J. Appl. Phys., 31, L1514 (1992).

\section{DISCLAIMER}

This report was prepared as an account of work sponsored by an agency of the United States Government. Neither the United States Government nor any agency thereof, nor any of their employees, makes any warranty, express or implied, or assumes any legal liability or responsibility for the accuracy, completeness, or usefulness of any information, apparatus, product, or ence herein to any specific conts that its use would not infringe privately owned rights. Refermanufacturer, or specific commercial product, process, or service by trade name, trademark, mendation, or favoring by the not necessarily constitute or imply its endorsement, recomand opinions of authors the United States Government or any agency thereof. The views United States Government or any agency do not necessarily state or reflect those of the 